This item was submitted to Loughborough's Research Repository by the author.

Items in Figshare are protected by copyright, with all rights reserved, unless otherwise indicated.

\title{
Effect of tapered roller bearing supports on the dynamic behaviour of hypoid gear pair differentials
}

\section{PLEASE CITE THE PUBLISHED VERSION}

http://dx.doi.org/10.1177/0954407015598677

\section{PUBLISHER}

(C) IMechE 2015

\section{VERSION}

AM (Accepted Manuscript)

\section{PUBLISHER STATEMENT}

This work is made available according to the conditions of the Creative Commons Attribution-NonCommercialNoDerivatives 4.0 International (CC BY-NC-ND 4.0) licence. Full details of this licence are available at: https://creativecommons.org/licenses/by-nc-nd/4.0/

\section{LICENCE}

CC BY-NC-ND 4.0

\section{REPOSITORY RECORD}

Mohammadpour, Mahdi, P.M. Johns-Rahnejat, Stephanos Theodossiades, and Homer Rahnejat. 2019. "Effect of Tapered Roller Bearing Supports on the Dynamic Behaviour of Hypoid Gear Pair Differentials". figshare. https://hdl.handle.net/2134/18576. 


\title{
Effect of Tapered Roller Bearing Supports on the Dynamic Behaviour of Hypoid Gear Pair Differentials
}

\author{
M. Mohammadpour, P.M. Johns-Rahnejat, S. Theodossiades and H. Rahnejat \\ Wolfson School of Mechanical \& Manufacturing Engineering, Loughborough University, \\ Loughborough, UK, LE111UW
}

Corresponding author: H. Rahnejat, Email: H.Ranejat@lboro.ac.uk, Tel: +44 (0)1509 227569

\begin{abstract}
Noise and vibration refinement, and energy efficiency are the key drivers in power train development. The final drive (differential) is a source of vibration concern and also contributes to power train inefficiency. To optimise differential characteristics for the key issues of refinement and efficiency detailed models of gear interactions as well as support bearing dynamics is required. This study reports on an integrated lubricated bearing and gear contacts with 8 degrees-of-freedom dynamic analysis (tribo-dynamic model). NonNewtonian shear behaviour of thin lubricant film conjunctions is taken into account the integrated tribo-dynamic analysis has not hitherto been reported in literature. The results show that the transmitted vibration spectra from the system onto the differential casing are dominated by bearing frequencies rather than the meshing of gears. This effect becomes more significant with higher bearing preload which extends the bearing loaded region and thus reduces the bearing compliance effect. It is also revealed that sufficient bearing preload improves vibration refinement, but can lead to marginally reduced transmission efficiency.
\end{abstract}


Keywords: Roller bearing dynamics, Hypoid gear pairs, Vehicle refinement, Transmission efficiency, Automotive differential

\section{Nomenclature}

$A_{a}$ - Asperity contact area

$A_{f}$ - Vehicle frontal area

$a$ - Vehicle acceleration

$b$ - Half amount of backlash

C - Radial bearing clearance

$C_{D}$ - Drag coefficient of vehicle

$c^{\prime}$ - Solid surfaces thermal capacity

$c_{m}$ - coefficient of hysteretic damping

$c_{p x}$ - Pinion bearing damping in $\mathrm{x}$ direction

$c_{p y}$ - Pinion bearing damping in y direction

$c_{p z}$ - Pinion bearing damping in z direction

$c_{g x}$ - Gear bearing damping in $\mathrm{x}$ direction

$c_{g y}$ - Gear bearing damping in y direction

$c_{g z}$ - Gear bearing damping in z direction

$E^{\prime}$ - Reduced Young's elastic modulus of elasticity: $2 /\left(\left(1-\vartheta_{p}^{2}\right) / E_{p}+\left(1-\vartheta_{g}^{2}\right) / E_{g}\right)$

$E_{r}$ - Reduced elastic modulus of the contact: $\pi E^{\prime} / 2$

$E_{p}$ - Young's modulus of elasticity of the pinion

$E_{g}$ - Young's modulus of elasticity of the gear

$e(t)$ - Static unloaded transmission error

$F_{a}$ - Bearing axial load 
$F_{r 1}, F_{r 2}$ - Radial load of bearing

$F_{f l}$ - Normal flank load

$F_{t}$ - Total meshing load

$f_{r}$ - Total flank friction

$f_{r l}$ - Tyre-road coefficient of rolling resistance

$f_{b}$ - Boundary friction contribution

$f_{m}$ - Meshing frequency

$f_{v}$ - Viscous friction contribution

$H_{i}-$ Film thickness in roller-to-race contact

$h_{c 0}$ - Dimensionless central film thickness

$I_{p}$ - Moment of inertia of the pinion

$I_{g}$ - Moment of inertia of the gear

$\dot{K}$ - Lubricant conductivity

$K^{\prime}$ - Solid surface conductivity

$K_{n}$ - Inner ring - rolling element - outer ring effective stiffness non-linearity

$k_{m}(t)$ - Meshing stiffness

$k_{p x}$ - Pinion bearing stiffness in $\mathrm{x}$ direction

$k_{p y}$ - Pinion bearing stiffness in y direction

$k_{p z}$ - Pinion bearing stiffness in z direction

$k_{g x}$ - Gear bearing stiffness in $\mathrm{x}$ direction

$k_{g y}$ - Gear bearing stiffness in y direction

$k_{g z}$ - Gear bearing stiffness in z direction

$M$ - Vehicle mass

$m_{p}, m_{g}$ - Masses of the pinion and gear

$n_{x}, n_{y}, n_{z}$ : Components of the instantaneous normal unit vectors of the flank contact

$P$ - Power loss 
$\bar{p}$ - Average pressure

$R_{p}(t), R_{g}(t)$ - Pinion and gear principal contact radii

$R_{a}$ - Aerodynamic resistance

$R_{r l}$ - Rolling resistance

$R_{G}$ - Gravitational resistance

$r_{r o}-$ Roller radius

$r_{t}$ - Laden dynamic tyre radius

$R^{\prime}$ - Equivalent radius of contact

$T_{a p}, T_{a g}$ - Applied torque to the pinion and gear

$T_{p}, T_{g}$ - Externally applied torque to the pinion and gear

$T_{f r p}, T_{f r g}$ - Frictional moments at pinion and gear

$U^{\prime}$ - Speed of entraining motion of the lubricant

$U_{g}$ - The component of gear motion along the instantaneous line of action

$U_{p}$ - The component of pinion motion along the instantaneous line of action

$U_{r o}, U_{r i}-$ Surface speeds of rollers and rings

$V$ - Vehicle speed

$W$ - Vehicle weight

$W_{a}$ - Load carried by surface asperities

$W_{i}$ - Load carried by a typical rolling element

$x_{a}$ - General form of axial displacement of bearing

$x_{p}$ - Pinion lateral displacement in $\mathrm{x}$ direction

$x_{g}$ - Gear lateral displacement in x direction

$r 1, r 2$ - General form of radial displacements of bearing

$y_{p}$ - Pinion lateral displacement in y direction

$y_{g}$ - Gear lateral displacement in y direction

$z_{p}$ - Pinion lateral displacement in z direction

$z_{g}$ - Gear lateral displacement in z direction 
Greek symbols:

$\alpha$ - Pressure viscosity coefficient

$\beta$ - Average asperity tip radius

$\varepsilon-$ Transmission efficiency

$\gamma$-Slope of the lubricant limiting shear stress-pressure dependence

$\delta_{i}$ - Contact deflection of roller $i$

$\eta_{0}$ - Lubricant dynamic viscosity at atmospheric pressure

$\theta_{i}$ - Angular position of roller $i$

$\lambda$ - Stribeck’s oil film parameter

$\lambda_{c r^{-}}$Critical film ratio

$\mu$ - Coefficient of friction

$v_{p}, v_{g}$ - Poisson's ratio of the pinion and gear material

$\xi$ - Asperity density per unit area

$\rho$ - Density of air

$\rho^{\prime}$ - Solid surface density

$\bar{\rho}$ - Bearing radial interface fitting

$\sigma$ - Composite RMS surface roughness $\left(\sigma=\sqrt{\sigma_{1}^{2}+\sigma_{2}^{2}}\right)$

$\sigma_{1}, \sigma_{2}$ - Surface roughness of contiguous solids

$\tau_{0}$ - Eyring shear stress of the lubricant

$\tau_{L 0}$ - Limiting shear stress of the lubricant

$\Lambda$ - Bearing contact angle

$\varphi_{p}, \varphi_{g}$ - Pinion and gear rotational displacement

$\psi-$ Angled entraining motion of the lubricant

\section{Introduction}


Noise, Vibration and Harshness (NVH) refinement and transmission efficiency are key desired attributes of automotive power trains. Transmission efficiency of the system has gained particular importance in recent times as the result of increasingly stringent directives on emission levels, as well as desired reduced fuel consumption. This has led to the trend towards light-weight and compact power trains. Therefore, prediction of transmission efficiency calls for accurate dynamic analysis.[1]. Additionally, $\mathrm{NVH}$ refinement is progressively regarded as a sign of power train quality, thus the need to avoid a plethora of noise and vibration concerns such as rattle [2-5], clonk [6] and axle whine [7,8] which are associated with the modern light weight and compact power trains.

Gearing mechanisms are widely used in many engineering applications, therefore subject of extensive studies. Most contributions have dealt with the dynamics of parallel axis transmissions [9-14], with fewer studies dedicated to non-parallel axis configurations such as hypoid and bevel gears. This has been because of the complexity of gear kinematics and meshing characteristics.

Remmers [15] considered a mass-elastic model of rear axle gears with infinite meshing stiffness in order to predict the pinion resonance. He carried out experiments to confirm the predicted vibration peaks. Kiyono et al. [16] derived a two degrees-of-freedom vibration model of a pair of bevel gears in which the line-of-action vector was simulated by a sine curve. He used the devised model to conduct stability analyses. Donley et al. [17] developed a dynamic model of a hypoid gear set for use in finite element analysis of gearing systems. In their gear mesh model, the mesh point and the line-of-action were considered as time invariant. Recently, Cheng and Lim [18,19] proposed a hypoid gear kinematic model, based on the exact gear geometry for analysis of gear meshing mechanism. They used their linear dynamic model to study the hypoid gear pair dynamics with the presence of transmission error excitations. Later Jiang and Lim [20] derived a dynamic model for hypoid gear pairs in 
order to investigate the system response. They represented the key meshing parameters; transmission error, contact stiffness, line-of-action and the contact point in the form of fundamental harmonics of a perfect sinusoid. Wang et al [21] developed a multi-point mesh model and applied it for the analysis of hypoid gear dynamics.

Thus far, most reported dynamic models assume dry contact analysis of meshing teeth, which is an unrealistic assumption with regard to the estimation of gear teeth pair conjunctional friction. For hypoid gear pairs the thickness of a film of lubricant can be predicted, prior to ascertaining the regime of lubrication and thus the contributions due to viscous shear of the lubricant film and any direct interaction of the surfaces (boundary friction). An analytical treatment is highlighted by Karagiannis et al [22], using the Grubin’s lubricant film thickness equation as a function of contact load and sliding velocity [23]. Whilst the use of an extrapolated equation reduces the computation times for transmissions with several teeth pairs in simultaneous mesh, these equations do not often accurately represent the prevailing contact conditions in the gear meshing problems. Mohammadpour et al. [24] presented a similar dynamic model to that of Karagiannis et al [22], but using the more appropriate lubricant film formula of Chittenden et al. [25], which is applicable for elliptical contact footprint geometry of hypoid gear teeth pair with angled lubricant entrainment into the contact conjunction. Later Mohammadpur et al [26] used Evans and Johnson [27] tractive lubricant model subject to non-Newtonian shear, a condition which is commonplace in highly loaded hypoid gears. Their previous 2 degrees-of-freedom gear pair tribo-dynamics model [24] was extended to 8-DOF, including lateral vibrations of transmission shafts [26].

In all the contributions concerning gear dynamics, the effect of bearing supports is either ignored or a linear representation of the bearings is made. Yet bearings are one of the limiting factors in the dynamic performance of all forms of rotating machinery. Therefore, in the current analysis nonlinear bearing dynamic behaviour is included. 
In gear applications and especially in hypoid gears, it is necessary to compute the instantaneous principal radii of curvature of the pinion and gear wheel teeth throughout meshing. Unlike the cylindrical gears, where these radii are easily determined through simple semi-analytic approaches [28], for hypoid gears it is essential to resort to Tooth contact Analysis (TCA). The method is outlined in detail by Litvin and Fuentes [29]. At any instant of time in the vehicular differential hypoid gears, several teeth pairs are in simultaneous mesh to carry the high generated torques. TCA calculates the load share per pair of teeth at any instant throughout meshing, corresponding to their meshing stiffness and the static transmission error. Using this approach all alignment, manufacturing and assembly errors can be accommodated. Recently, Kolivand and Kahraman [30] presented a different approach to the TCA, termed ease of topology method.

In the current analysis CALYX is used, based on the work of Vijayakar [31]. All the acquired data from TCA (for example the non-linear meshing stiffness) are introduced in the form of periodic Fourier series in the dynamic model.

The current dynamic model includes a hypoid gear pair supported by tapered roller bearings. The model takes into account the variable load characteristics of gear meshing. The model of rolling element bearing is dynamic, enabling inclusion of main bearing frequencies as the cage frequency or its base natural frequency. The dynamic model is coupled with a tribological model which together form the tribo-dynamic model. This coupling is due to the physical connections of these two models requiring a multi-physics approach. The tribological model provides the frictional losses as a source of energy sink and damping in the dynamic model.

On the other hand, the dynamic model provides the required input information such as the contact load and the contact kinematics to the tribological model. These terms are required in calculating the frictional forces and lubricant film thickness. 
Results show that bearing cage and base natural frequencies are more dominant than the meshing frequency of the gearing system caused by the Dynamic Transmission Error (DTE) and the lateral oscillations of the supporting transmission shafts. Some of these contributions are not observed with linear bearing models or those which do not take into account the dynamics of rolling element bearing supports. This new feature of the model not only changes the dynamic predictions, but also changes the predictions with regard to transmission efficiency as well as NVH response of the system. The combined simultaneous study of transmission efficiency and NVH refinement has not hitherto been reported in literature and constitutes the main contribution of the current analysis.

\section{Methodology}

\subsection{Dynamic model:}

\subsubsection{Equations of motion:}

The mechanical system of the hypoid gear pair (Fig. 1) comprises eight degrees of freedom (lateral/axial and torsional motions of the transmission shafts). Shaft bending slope effects have not been considered as the evidence in the literature points to their rather insignificant influence. This has been demonstrated experimentally by Fujii et al. [32]), and numerically by Yinong et al. [33] and Yang and Lim [34]) for similar systems as that investigated here. In addition, the centred position of the gear wheel between symmetric bearing supports (similar to the configuration of cylindrical gears) and the relatively stiff carrier shaft of the gear makes the bending slope even less significant. The inertial properties of the mating gear pair are listed in Table 1. 


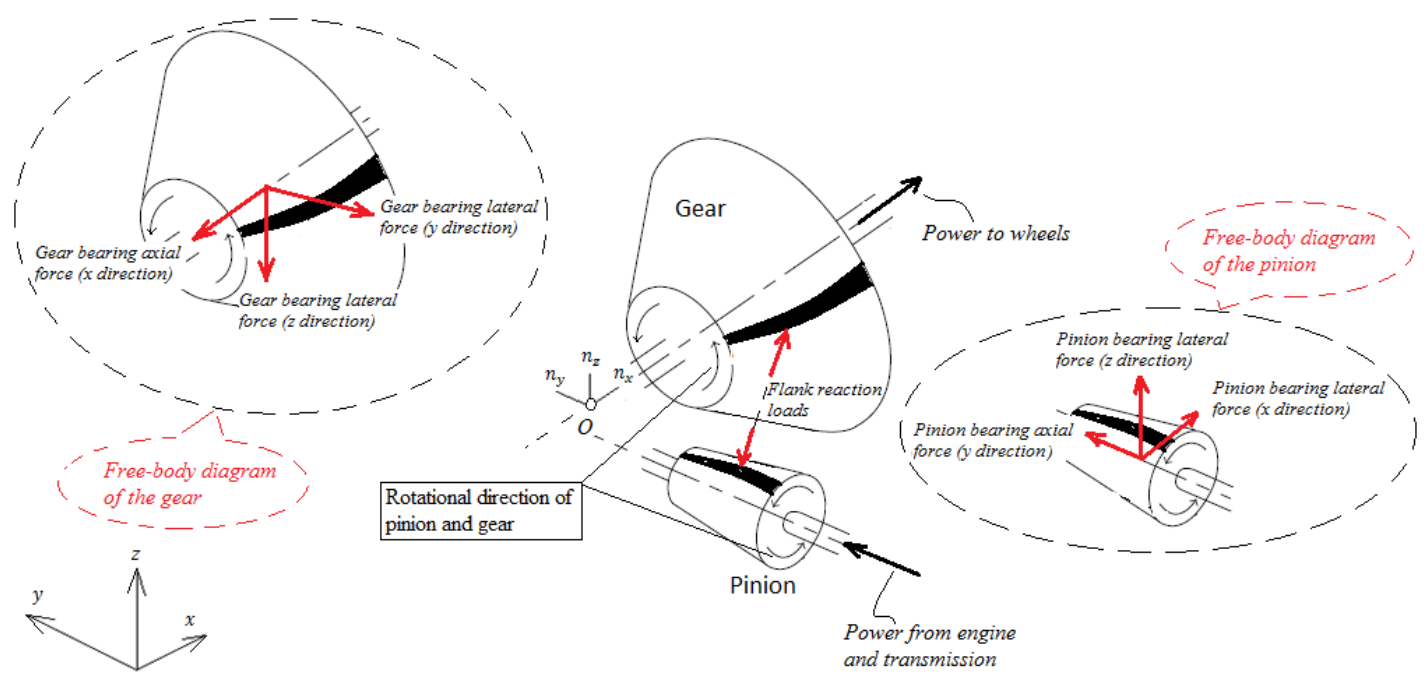

Figure 1: The corresponding free body diagrams

Table 1: Inertia/mass properties

\begin{tabular}{|c|c|c|c|}
\hline Part number & Part name & Inertia $\left[\mathbf{k g ~ m}^{\mathbf{2}}\right]$ & Mass $[\mathbf{k g}]$ \\
\hline 1 & Ground & ----- & ----- \\
\hline 2 & Pinion & $1734 \times 10^{-6}$ & 12 \\
\hline 3 & Gear & $5.81 \times 10^{-2}$ & 49.9 \\
\hline
\end{tabular}

The equations of motion are obtained as:

$$
\left\{\begin{array}{l}
I_{p} \ddot{\varphi}_{p}+R_{p} c_{m} \dot{x}+R_{p} k_{m} f(x)=T_{p} \\
I_{g} \ddot{\varphi}_{g}-R_{g} c_{m} \dot{x}-R_{g} k_{m} f(x)=-T_{g} \\
m_{p} \ddot{x}_{p x}+c_{p x} x_{p x}+k_{p x} x_{p x}-n_{x} \times\left(c_{m} \dot{x}+k_{m} f(x)\right)=0 \\
m_{p} \ddot{x}_{p y}+c_{p y} x_{p y}+k_{p y} x_{p y}-n_{y} \times\left(c_{m} \dot{x}+k_{m} f(x)\right)=0 \\
m_{p} \ddot{x}_{p z}+c_{p z} \dot{x}_{p z}+k_{p z} x_{p z}-n_{z} \times\left(c_{m} \dot{x}+k_{m} f(x)\right)=0 \\
m_{g} \ddot{x}_{g x}+c_{g x} x_{g x}^{\cdot}+k_{g x} x_{g x}+n_{x} \times\left(c_{m} \dot{x}+k_{m} f(x)\right)=0 \\
m_{g} \ddot{x}_{g y}+c_{g y} x_{g y}+k_{g y} x_{g y}+n_{y} \times\left(c_{m} \dot{x}+k_{m} f(x)\right)=0 \\
m_{g} \ddot{x}_{g z}+c_{g z} x_{g z}+k_{g z} x_{g z}+n_{z} \times\left(c_{m} \dot{x}+k_{m} f(x)\right)=0
\end{array}\right.
$$

where $x$ represents the DTE which is defined as the teeth relative displacement along the instantaneous line of approach between the engaged teeth pairs and can be written as: 
$x(t)=\int_{0}^{t} R_{p} \dot{\varphi_{p}} d t-\int_{0}^{t} R_{g} \dot{\varphi_{g}} d t-U_{g}+U_{p}-e(t)$

where:

$U_{g}-U_{p}=n_{x} x_{g x}+n_{y} x_{g y}+n_{z} x_{g z}-n_{x} x_{p x}-n_{y} x_{p y}-n_{z} x_{p z}$

$U_{g}-U_{p}$ represents the contribution of the supporting bearing deflections (lateral and axial motions) in the DTE along the instantaneous line of action. These depend on the bearing specifications (stiffness, number of rolling elements etc.), as well as loading that originates from the flank meshing point. $e(t)$ represents the static unloaded transmission error, which is also calculated using TCA with zero applied torque. This is introduced in the model as a Fourier series.

In order to take into account the non-linear effects of backlash, the piece-wise linear function $f(x)$ has been introduced as:

$f(x)=\left\{\begin{array}{lr}x, & x \geq 0 \\ 0, & -2 b<x<0 \\ x+2 b, & x \leq-2 b\end{array}\right.$

where $b$ is half the total amount of backlash. There are two critical thresholds that represent severe NVH conditions. The first of these is teeth separation leading to single-sided impacts. This condition is defined as a combination of: $x(t)_{\max } \geq 0$ and $-2 b<x(t)_{\min }<0$. The second is an even worse condition when the teeth pairs exhibit double-sided impacts: $x(t)_{\max } \geq 0$ and $x(t)_{\min } \leq-2 b$.

$k_{m}$, the meshing stiffness is obtained through TCA (exhibiting non-linear dependence on the applied load) and is introduced to the system dynamics as a Fourier series with the teeth meshing period being the fundamental period of the series [26]. In fact, a map of meshing stiffness Fourier coefficients arising from the calculations for different loading conditions is provided to the model through use of CALYX. 
At the meshing point, the material hysteretic damping needs to be taken into account [35]. These damping forces are considered in the equation of motion (1). The required damping coefficient is obtained as:

$c_{m}=\frac{0.009 k_{m}}{f_{m}}$

In addition to the meshing stiffness, $n_{x}(t), n_{y}(t)$ and $n_{z}(t)$ are components of the instantaneous unit vectors in the direction of the line of action that are required in equations of motion (also obtained using TCA and employed in the model as Fourier series). This normal vector varies from point to point and with the pinion angle of rotation. $R_{p}(t)$ and $R_{g}(t)$ are the instantaneous principal radii of contact for the pinion and the gear, respectively, which are defined at every point of contact as well. They are also calculated through TCA and introduced in the dynamics model as Fourier series. Therefore, all these terms are time (pinion angle) variants. The general form of the Fourier series expression for these variables is:

$f(t)=\frac{a_{0}}{2}+\sum_{n=1}^{\infty}\left[a_{n} \cos \left(n \varphi_{p}\right)+b_{n} \sin \left(n \varphi_{p}\right)\right]$

These functions are represented with respect to the pinion angle of rotation, using the teeth meshing period as the fundamental period of the series.

\subsubsection{Excitation torques:}

The excitation $T_{i}(i=p, g)$ in torsional directions comprises the applied torques on the pinion and the ring gear, as well as the contribution due to flank friction:

$T_{i}=T_{a i}+T_{f r i}$

The tractive torque at the road wheels (which is transmitted to the gear wheel) includes the rolling resistance $\left(R_{r l}\right)$, aerodynamic resisting force $\left(R_{a}\right)$ and any grading load $\left(R_{G}\right)$ [36]: 
$T_{a g}=r_{t} \sum F=r_{t}\left(R_{a}+R_{r l}+R_{G}\right)$

where $r_{t}$ is the laden dynamic tyre radius and:

$R_{a}=\frac{\rho}{2} C_{D} A_{f} V^{2}, \quad R_{r l}=f_{r l} W$

$f_{r l}$ is the coefficient of rolling resistance and $W$ is the vehicle weight. $R_{G}$ is zero for vehicle motion on a flat road (zero grading).

The instantaneous input torque from the engine (resident on the pinion) is defined as:

$T_{a p}=\frac{R_{p}}{R_{g}} T_{a g}$

The friction generated between the engaged gear teeth pairs contributes to the system excitation as an additional internal damping term. A thin elastohydrodynamic lubricant film is assumed to form between the meshing teeth pairs, which is subject to non-Newtonian viscous shear, supplemented by any asperity interactions (boundary friction as the result of the direct contact of surfaces). Therefore:

$$
T_{\text {fri }}=R_{i} f_{r}
$$

where, the flank friction is given by:

$$
f_{r}=f_{v}+f_{b}
$$

$f_{v}$ is the viscous friction with coefficient of friction, $\mu$ and normal load on the flank, $F_{f l}$ :

$$
f_{v}=\mu F_{f l}
$$

An analytical-experimental equation for the calculation of the viscous coefficient of friction is used, considering the non-Newtonian behaviour of the thin lubricant film and thermal effects [27]. This equation is derived in the generic form covering both Newtonian and non- 
Newtonian regimes. An analytical approach for thermal thinning is embedded in this equation in order to take in to account the thermal effects. Results have been validated against experimentally measured friction values from the disk machine experiment:

$\mu=0.87 \alpha \tau_{0}+1.74 \frac{\tau_{0}}{\bar{p}} \ln \left(\frac{1.2}{\tau_{0} h_{c 0}}\left(\frac{2 \dot{K} \eta_{0}}{1+9.6 \zeta}\right)^{1 / 2}\right)$

where:

$\zeta=\frac{4}{\pi} \frac{\dot{K}}{h_{c 0} / R^{\prime}}\left(\frac{\bar{p}}{E^{\prime} R^{\prime} K^{\prime} \rho^{\prime} c^{\prime} U^{\prime}}\right)^{1 / 2}$

To calculate boundary friction $f_{b}$, the method presented by Greenwood and Tripp [37] is used, where a Gaussian distribution of asperity heights is assumed, with a mean radius of curvature for an asperity summit. Boundary friction comprises non-Newtonian shear of thin films, as well as adhesive elasto-plastic friction of opposing asperities, thus:

$f_{b}=\tau_{L 0} A_{a}+\gamma W_{a}$

$\gamma$ is analogous to the adhesive coefficient of friction at asperity level junctions and $\tau_{L 0}$ is the lubricant limiting shear stress [38]. A share of the contact load, $W_{a}$, is carried by the asperities with the total asperity contact area, $A_{a}$, thus [37]:

$W_{a}=\frac{16 \sqrt{2}}{15} \pi(\xi \beta \sigma)^{2} \sqrt{\frac{\sigma}{\beta}} E^{\prime} A F_{5 / 2}(\lambda)$

$A_{a}=\pi^{2}(\xi \beta \sigma)^{2} A F_{2}(\lambda)$

According to Greenwood and Tripp [37], the roughness parameter $(\xi \beta \sigma)$ is reasonably constant with values in the range of $0.03-0.07$ for steel surfaces. The ratio $\sigma / \beta$ is a representation of the average asperity slope, in the range of $10^{-4}-10^{-2}$ [39]. In the current study it is assumed that $\sigma_{1}=\sigma_{2}, \xi \beta \sigma=0.055$ and $\sigma / \beta=0.001$. 
The statistical functions $F_{2}(\lambda)$ and $F_{5 / 2}(\lambda)$ are expressed as [39]:

$F_{5 / 2}(\lambda)=\left\{\begin{array}{rr}-0.004 \lambda^{5}+0.057 \lambda^{4}-0.296 \lambda^{3}+0.784 \lambda^{2}-1.078 \lambda+0.617 ; & \text { for } \lambda \leq \lambda_{c r} \\ 0 \quad & \text { for } \lambda>\lambda_{c r}\end{array}\right.$

$F_{2}(\lambda)=\left\{\begin{array}{rr}-0.002 \lambda^{5}+0.028 \lambda^{4}-0.173 \lambda^{3}+0.526 \lambda^{2}-0.804 \lambda+0.500 ; & \text { for } \lambda \leq \lambda_{c r} \\ 0 \quad & \text { for } \lambda>\lambda_{c r}\end{array}\right.$

$\lambda=\frac{h}{\sigma}$ is Stribeck's oil film parameter, where $\sigma$ is the composite root mean square roughness of the contiguous surfaces. $\lambda_{c r} \simeq 3$ is the critical film ratio below which a mixed regime of lubrication (including asperity interactions) is expected to occur [39].

The frictional power loss is obtained as:

$P=f_{r}\left|U_{p}-U_{g}\right|$

The percentage transmission efficiency is obtained as:

$\varepsilon=\frac{T_{p} \dot{\varphi}_{p}-P}{T_{p} \dot{\varphi}_{p}} \times 100$

The film thickness $h$ is required for friction calculations. This can be obtained using an extrapolated oil film thickness expression for elliptical point contacts with angled lubricant flow entrainment [25]:

$$
h_{c 0}^{*}=4.31 U^{* 0.68} G^{* 0.49} W^{* 0.073}\left\{1-\exp \left[-1.23\left(\frac{R_{s}}{R_{e}}\right)^{2 / 3}\right]\right\}
$$

where, the non-dimensional groups are:

$W^{*}=\frac{\pi F_{f l}}{2 E_{r} R_{e}^{2}}, \quad U^{*}=\frac{\pi \eta_{0} U^{\prime}}{4 E_{r} R_{e}}, \quad G^{*}=\frac{2}{\pi}\left(E_{r} \alpha\right), \quad h_{c 0}^{*}=\frac{h_{c 0}}{R_{e}}$,

and

$\frac{1}{R_{e}}=\frac{\cos ^{2} \psi}{R_{z x}}+\frac{\sin ^{2} \psi}{R_{z y}}, \frac{1}{R_{s}}=\frac{\sin ^{2} \psi}{R_{z x}}+\frac{\cos ^{2} \psi}{R_{z y}}$ 


\subsection{Tooth Contact Analysis (TCA):}

The TCA method is described in detail by Litvin and Fuentes [29]. The main points of the approach are briefly described here. The contact load $F_{f l}$ for all the simultaneously meshing gear teeth pairs is calculated and the data obtained include the instantaneous principal contact radii of curvature of the teeth surfaces, the teeth pair contacts' stiffness and the static transmission error. The contact load per teeth pair is a function of the dynamic response. However, its distribution among the teeth pairs in simultaneous contact is defined quasistatically (for an assumed equal amount of the total contact load). A load distribution factor is calculated as a function of the pinion angle for all teeth pair contacts. This is the ratio of the applied load $F_{f l}$ on a given flank under consideration to the total transmitted load $F_{t}$ [40]:

$l f=\frac{F_{f l}}{F_{t}}$

Full details about the face-hobbed, lapped hypoid gear pair used in this study are provided in Mohammadpour et al [41].

\subsection{Bearing model:}

Rolling elements in a rolling element bearing carry a share of applied load in an oscillatory manner. Therefore, a quasi-static investigation of applied load on one rolling element would not be realistic; the variation of applied load in the time domain needs to be taken into account. These load fluctuations become more important when the transient squeeze film effect is considered in the lubricated contact model, where they cause rapid changes in lubricant film thickness with time and a more significant change in the rate of lubricant film squeeze effect. 
The bearing model is developed for a tapered roller bearing based on the original work of Rahnejat and Gohar [42] for a deep groove ball bearing. The degrees of freedom considered for each bearing include the lateral motions of the bearing centre, shown in figure 2, as well as axial float. Any vibration of the centre of bearing causes oscillatory applied load variation on each rolling bearing in its orbital path.

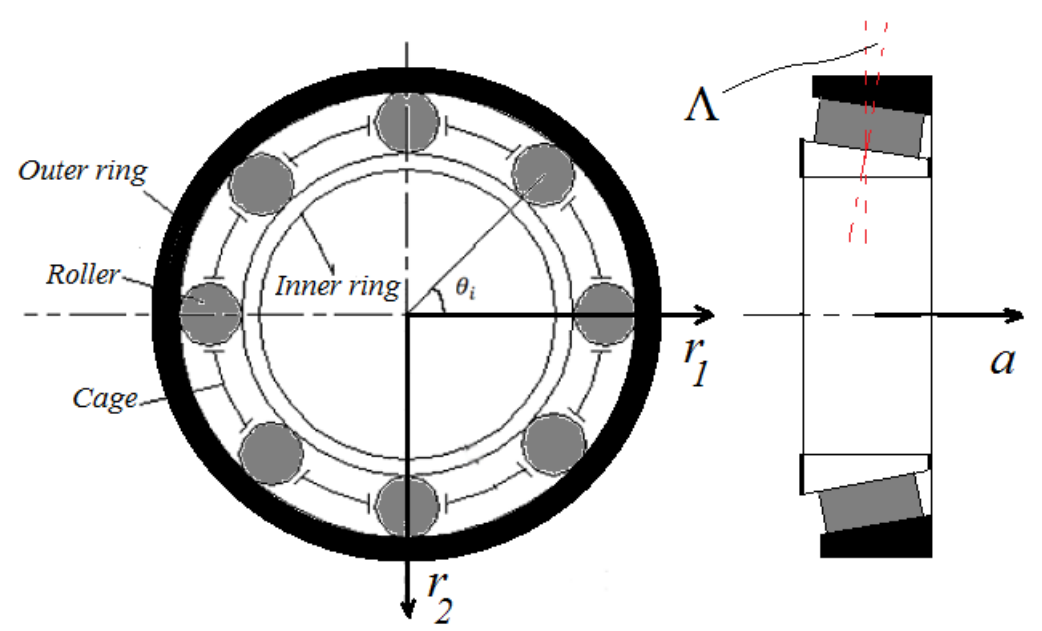

Figure 2: Bearing configuration

Instead of calculating the stiffness and damping coefficients $\left(k_{k l}, c_{k l}, k=p, g\right.$ and $\left.l=x, y, z\right)$ in the radial and axial directions at any step of time, the bearing reactions are determined based on the system dynamics (local deflection at the instantaneous rolling elements' locations). The gear teeth flank contact load in the lateral and axial directions are the excitation sources, which lead to bearing deflection and consequently to bearing reaction force components in the respective degrees of freedom. This process is subjected to iteration until convergence is achieved for any given time step. The bearing reaction loads in the lateral and axial directions in general form are:

$\left\{\begin{array}{l}F_{r 1}=\sum_{i=1}^{m}-w_{i} \cos \theta_{i} \cos \Lambda \\ F_{r 2}=\sum_{i=1}^{m}-w_{i} \sin \theta_{i} \cos \Lambda \\ F_{a}=\sum_{i=1}^{m}-w_{i} \sin \Lambda\end{array}\right.$ 
where, $F_{r 1}$ and $F_{r 2}$ are bearing reactions in the transverse radial directions. $F_{a}$ is the bearing reaction in the direction of axial thrust. $m$ is the number of rolling element and $\theta_{i}(t)$ is the instantaneous angular position of the rolling element $i . W_{i}$ is the instantaneous contact load of the $i^{\text {th }}$ rolling element, obtained using Hertzian contact theory also accounting for hysteretic damping [35]:

$w_{i}=k_{n} \delta_{i}^{n}+\frac{0.009 n k_{n} \delta_{i}^{n-1} \dot{\delta}_{l}}{f_{m}}$

The second term correspond to the hysteretic damping based on the equation (4). $k_{n}$ is the effective contact stiffness non-linearity of inner ring-roller-outer ring compound contacts (in the direction of contact angle) and for line contact configuration, the exponent $n$ is equal to 10/9 [43]. $\delta_{i}$; the deflection of the $i^{\text {th }}$ contact, is calculated using the following geometrical equation [44]:

$2 \delta_{i}=2\left(H_{i}-C\right)+r 1 \cos \theta_{i} \cos \Lambda+r 2 \sin \theta_{i} \cos \Lambda+x_{a} \sin \Lambda$

where $C$ is the radial bearing clearance and $H_{i}$ is the $i^{\text {th }}$ lubricated contact film thickness, assumed to be the same for the rolling element to the inner and outer raceway grooves. Therefore, equations (24)-(26) should be solved simultaneously using an iterative process. If there is any bearing radial interference fit instead of clearance, in the above equation $C=-\bar{\rho}$.

For the film thickness calculation, Mostofi and Gohar [45] equation for the central film thickness of a line contact is used. This equation takes into account the lubricant squeeze film effects, $\vartheta_{i}=\frac{\partial H_{i}}{\partial t}$ :

$H_{i}=r_{\text {ro }}\left[13.924 W_{i}^{*-0.045} U^{* 0.647} G^{* 0.46}\left(1-0.75 e^{132 \vartheta_{i} / U}\right)\right]$

where:

$W_{i}^{*}=w_{i} E_{r} / r_{r o}{ }^{2}, U^{*}=\eta_{0} u E_{r} / r_{r o}, G^{*}=\alpha E_{r}, U=U_{r o}+U_{r i}$ 


\section{Results and Discussion}

The present work investigates the dynamics of a pair of differential hypoid gears in a light truck with a 4-cylinder, 4-stroke engine. A summary of the input parameters and physical properties of the system is provided in Tables A1 - A4 in Appendix 1. Results have been presented as a series of solutions for different vehicle speeds from $20 \mathrm{~km} / \mathrm{h}$ up to $100 \mathrm{~km} / \mathrm{h}$. The effects of bearing model on the dynamic behaviour of the gear pair have been investigated.

\subsection{Dynamic transmission error (DTE):}

As the most important NVH output of the gear dynamics model, the DTE has been presented in figure 3 for the complete vehicle speed sweep. In this figure the FFT spectra of DTE is plotted at each vehicle speed with a bearing preload of $2500 \mathrm{~N}$. The figure shows the contribution of different frequencies and their spectral disposition at different vehicle speeds. The main frequencies are the bearing base natural frequencies in the radial and axial directions $\left(f_{n r}\right.$ and $\left.f_{n a}\right)$ [42], as well as the gear meshing frequency $\left(f_{m}\right)$. The bearing natural frequency depends on the bearing preload, number of rollers and the bearing dynamic stiffness [44]. The effect of the bearing spectral contributions on the DTE has not hitherto been included in the previous gearing vibration problems [18, 19, 21, 22]. The meshing frequency increases with vehicle speed and crosses the bearing natural frequencies or their modulation effects $\left(f_{n r}+f_{n a} / 2\right)$. This can cause premature resonant conditions, leading to excessive system vibration. 


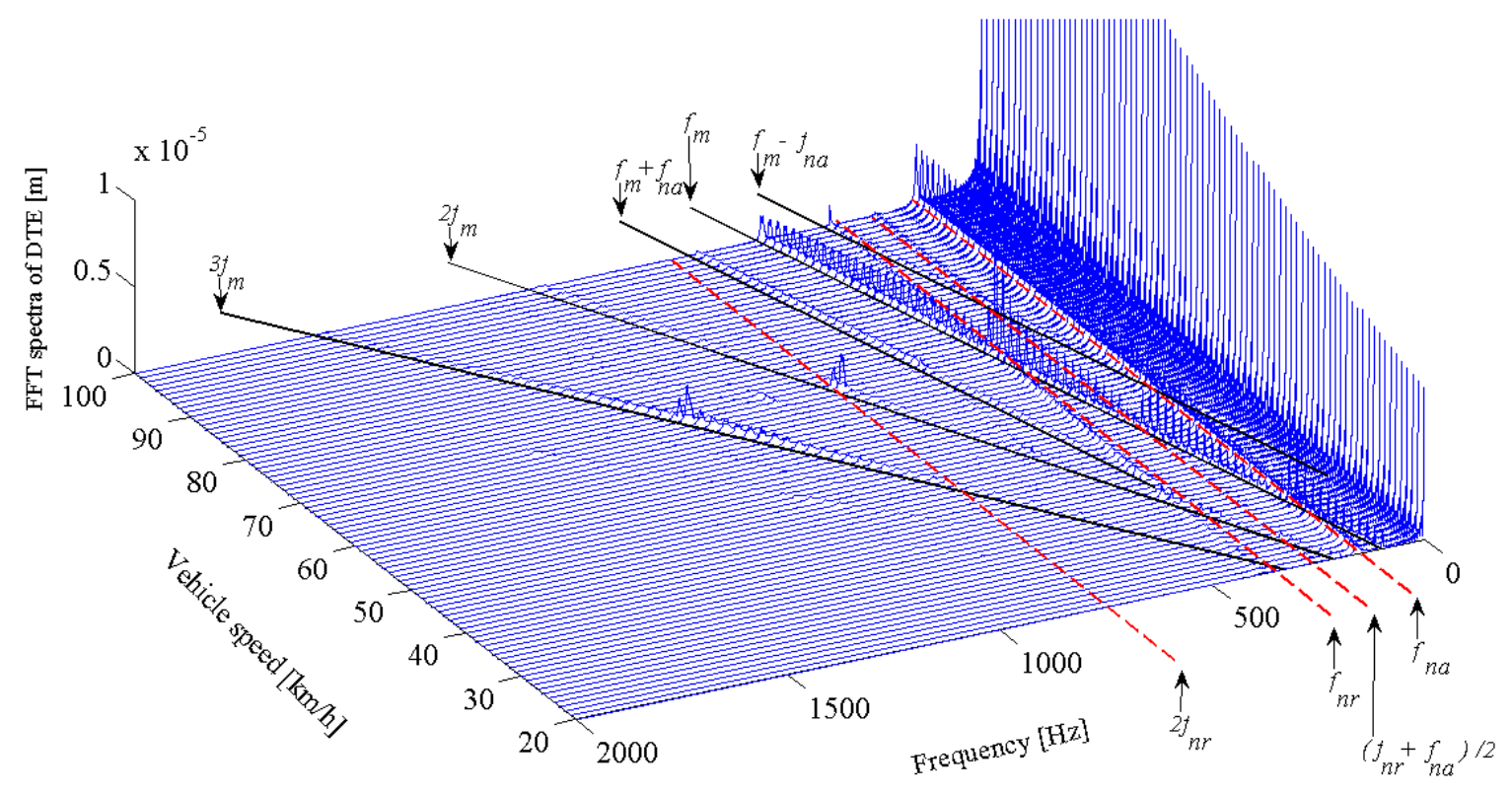

Figure 3: FFT spectra of DTE during the speed sweep (bearing preload=2500N)

Figure 4 presents the same results as in figure 3, but with a greater bearing preload of $6000 \mathrm{~N}$. The higher preload increases the base natural frequency of the bearing and therefore shifts the resonant speeds. 


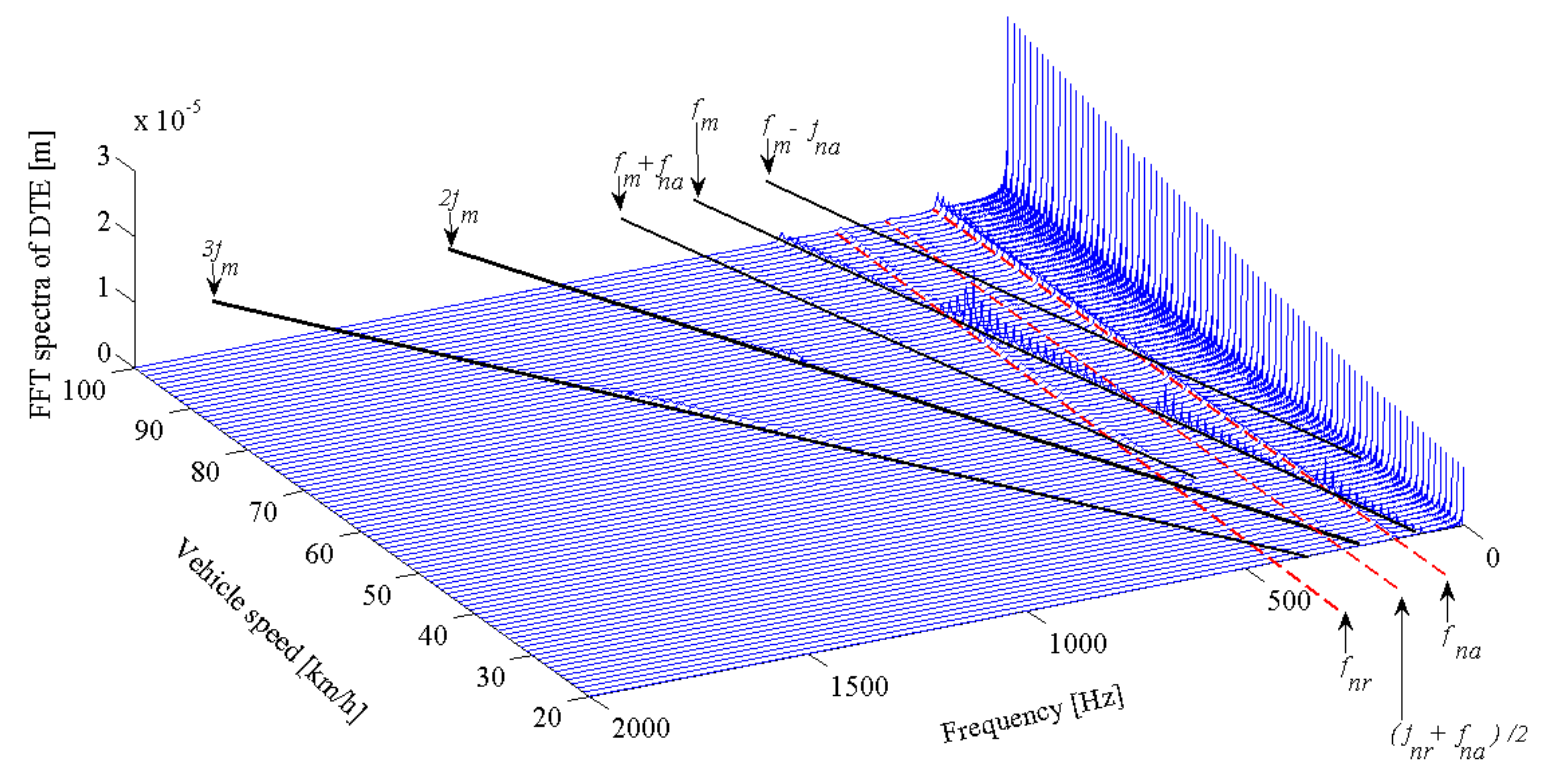

Figure 4: FFT spectra of DTE during the speed sweep (preload=6000N)

In order to observe the effect of preload, the maximum and minimum amplitudes of the DTE for different speeds are presented in figure 5. The overall amplitude of the DTE follows the same behaviour as that of the FFT spectra of figures 3 and 4 during the vehicle speed sweep. The higher preload shifts the occurrence of resonance to higher vehicle speeds. This causes the minimum value of DTE (in figure 5, which occurs at resonant conditions) to move away from the loss of contact and any subsequent teeth pair impact (DTE=0), yielding a more refined NVH condition. Another important parameter is the peak-to-peak value of DTE oscillations. The large oscillations in the DTE occur around the bearing natural frequency regions, which are indicated in figure 4. This is also reduced with an increasing bearing preload. 


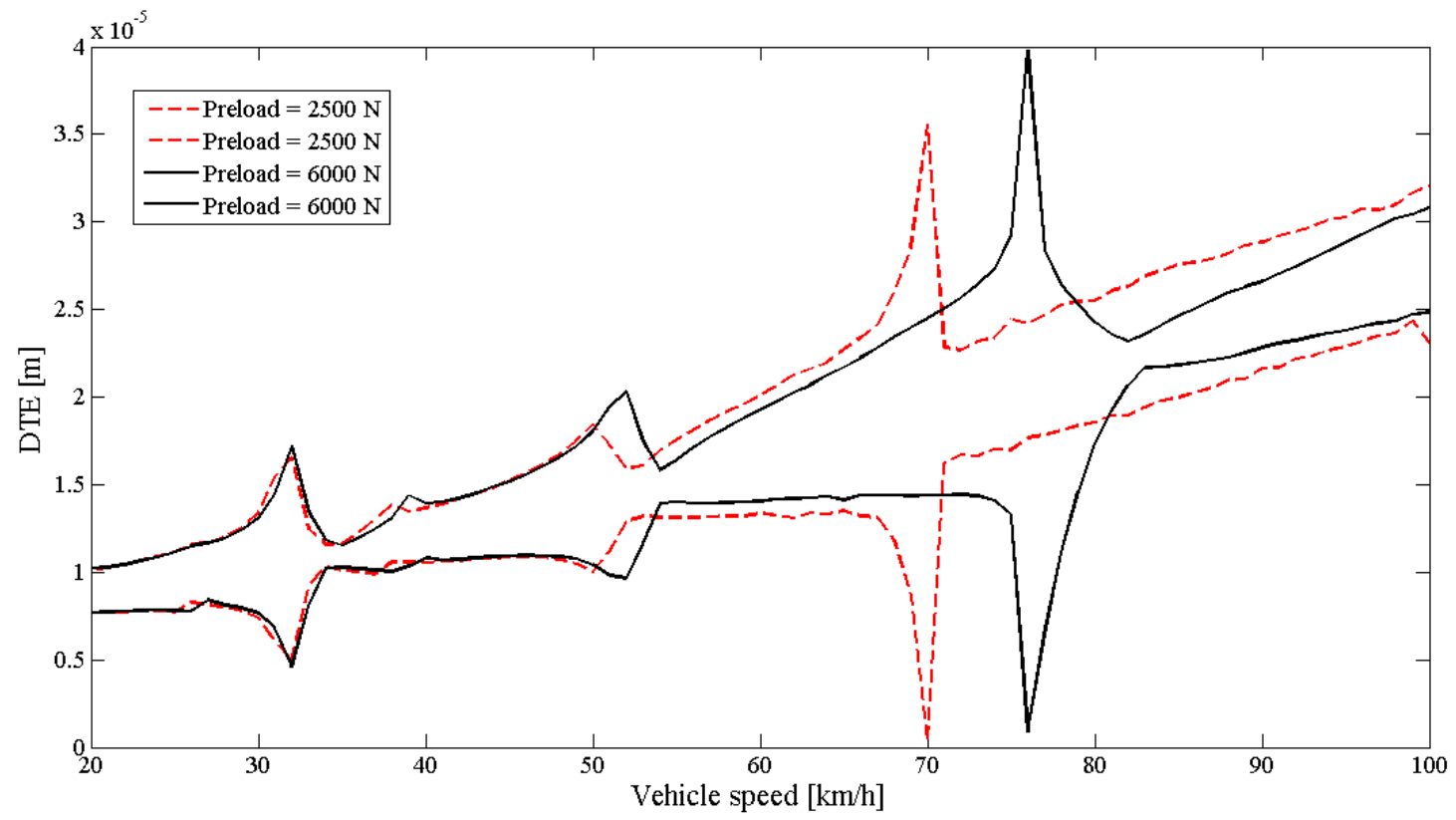

Figure 5: Maximum and minimum of DTE amplitude during the speed sweep

\subsection{Bearing radial displacement:}

Figure 6 presents the FFT spectra of radial displacement of the pinion during the speed sweep. The results show that the lateral motion of the pinion shaft, which would lead to the excitation of the differential axle casing, is dominated by the gear meshing and bearing base natural frequencies. 


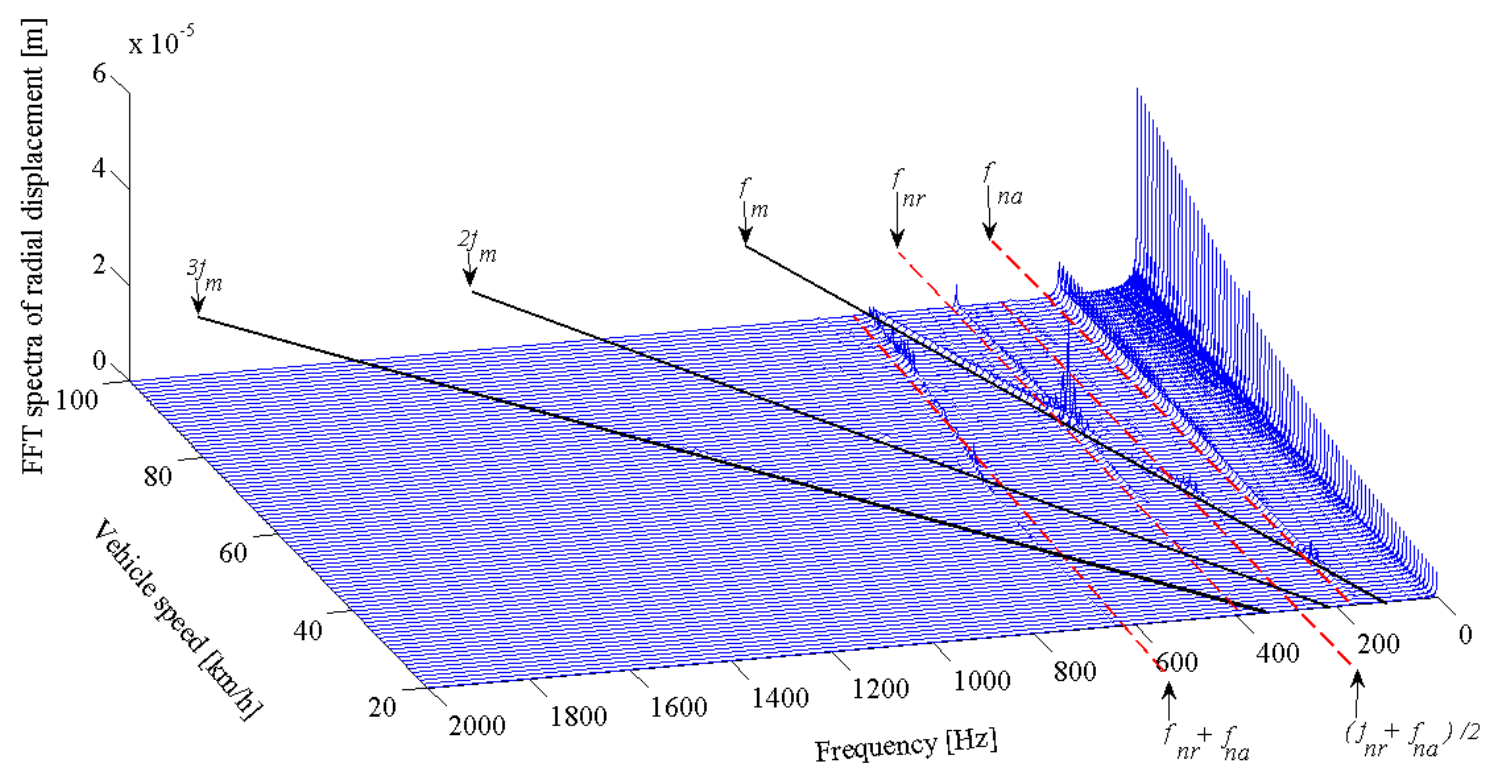

Figure 6: FFT spectra of radial displacement during the speed sweep (Bearing preload $=2500 \mathrm{~N}$ )

The figure shows that the bearing axial base natural frequency is more influential than that of gear meshing. Therefore, the rolling element bearings act like filters which dominantly pass their base natural frequency to the differential casing rather than the often presumed gear meshing frequency. Such behaviour would not be captured with a traditional model, representing the entire bearing by a series of stiffness and damping elements only (i.e. not taking into account the individual orbiting rolling element bearings’ contacts).

Figure 7 presents the same results as in figure 6, but for the higher bearing preload of $6000 \mathrm{~N}$. The figure shows that higher preloads (thus higher bearing dynamic stiffness) reduces the effect of bearing base natural frequencies and increases the effect of meshing frequency. This is because at a higher preload a more widely spread loaded region results in bearings, therefore less variation in dynamics stiffness through orbital motion of rolling elements. Therefore, there is a small degree of load variation per roller during a cage cycle. Hence, the effect of gear meshing frequency becomes more dominant. One interesting result in these 
figures is the important role of $2 \times \frac{\left(f_{n r}+f_{n a}\right)}{2}=f_{n r}+f_{n a}$ (instead of $2 \times f_{n r}$ which is observed in the DTE).

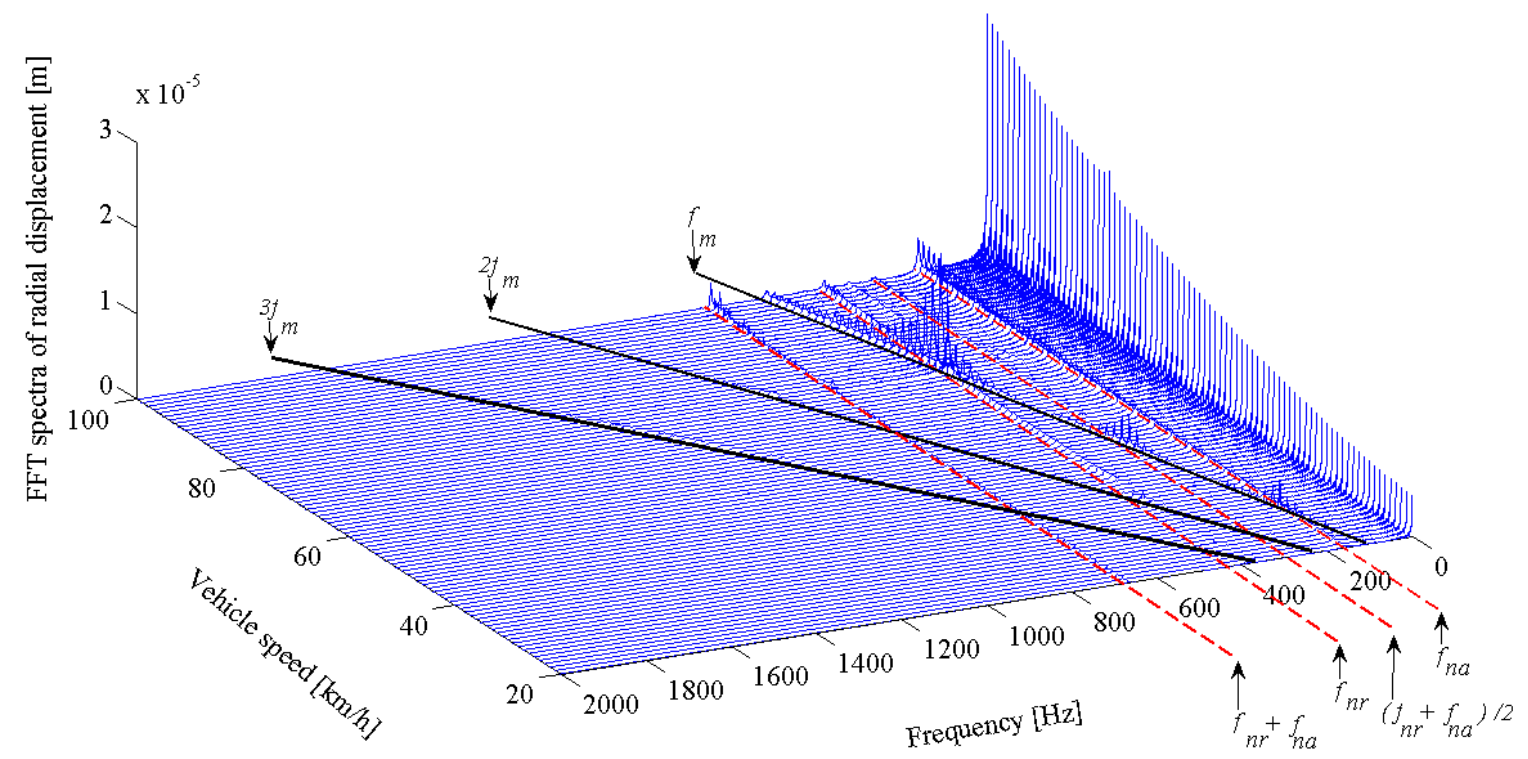

Figure 7: FFT spectra of radial displacement during the speed sweep (preload $=6000 \mathrm{~N}$ )

Figure 8 presents the maximum and minimum amplitudes of the radial displacement for different preloads. The figure shows that a higher bearing preload shifts any premature resonant conditions to the higher vehicle speeds, whilst also reducing the average amplitudes of oscillations. 


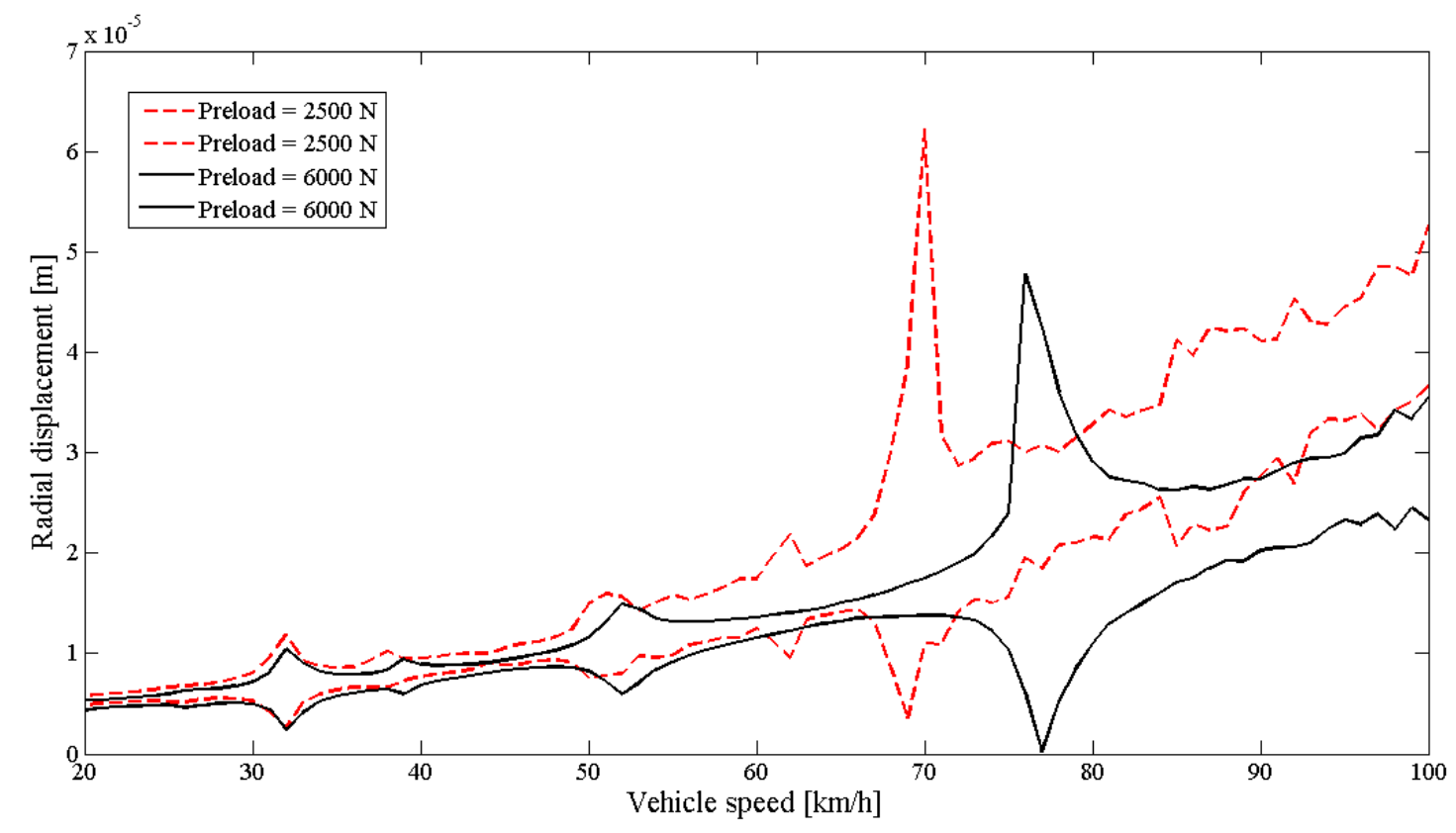

Figure 8: Maximum and minimum radial displacement amplitudes during the vehicle speed sweep

\subsection{Rolling element bearing load:}

Figure 9 is the FFT spectrum of varying load for a typical rolling element after several cage cycles and under steady state conditions. The cage frequency $f_{c}$ and its modulations with meshing and bearing base natural frequencies are evident. The meshing and bearing base natural frequencies and their modulations remain dominant. 


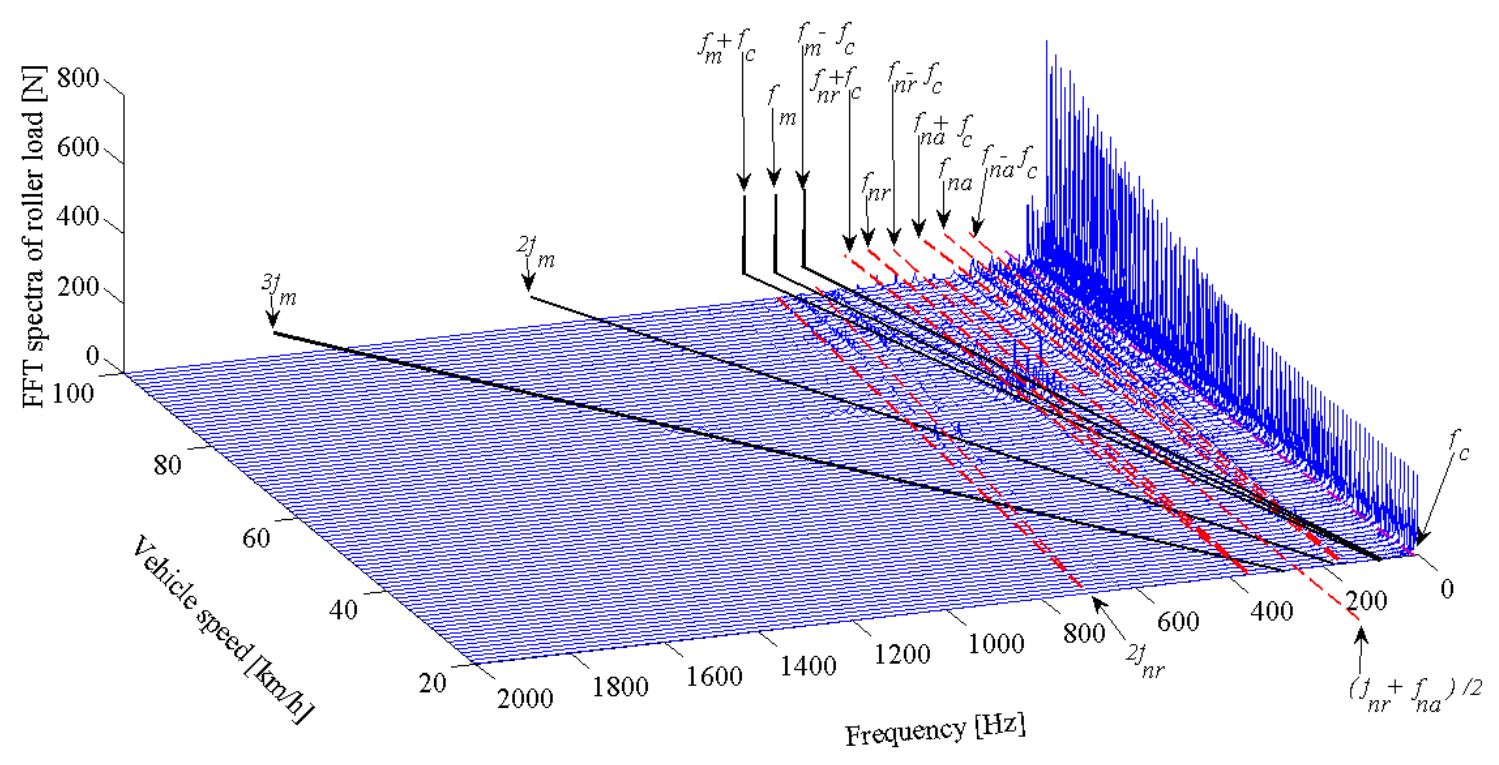

Figure 9: FFT spectra of roller load during the speed sweep (preload=2500N)

Figure 10 is the roller load trace for the higher preload. It shows that an increasing preload reduces the contribution at the cage frequency as already noted above. This also reduces the incidence of modulation effects. Figure 11 presents the maximum and minimum amplitude of the roller load trace. The main importance for such an output is the dynamic endurance of the bearing supports. The coincidence of bearing base natural frequency with the cage frequency or its multiples (speed-dependent frequencies) cause dynamic instability which may lead to damage and should, therefore, be avoided. These conditions often arise as the result of insufficient bearing preload or lack of interference fitting of bearings. Loss of rolling elements-to-races contacts (unloaded contacts) are good indications of such unfavourable conditions (i.e. zero contact load in this figure). Therefore, unloaded bearing zones can lead to bearing dynamic stability and worsening NVH. 


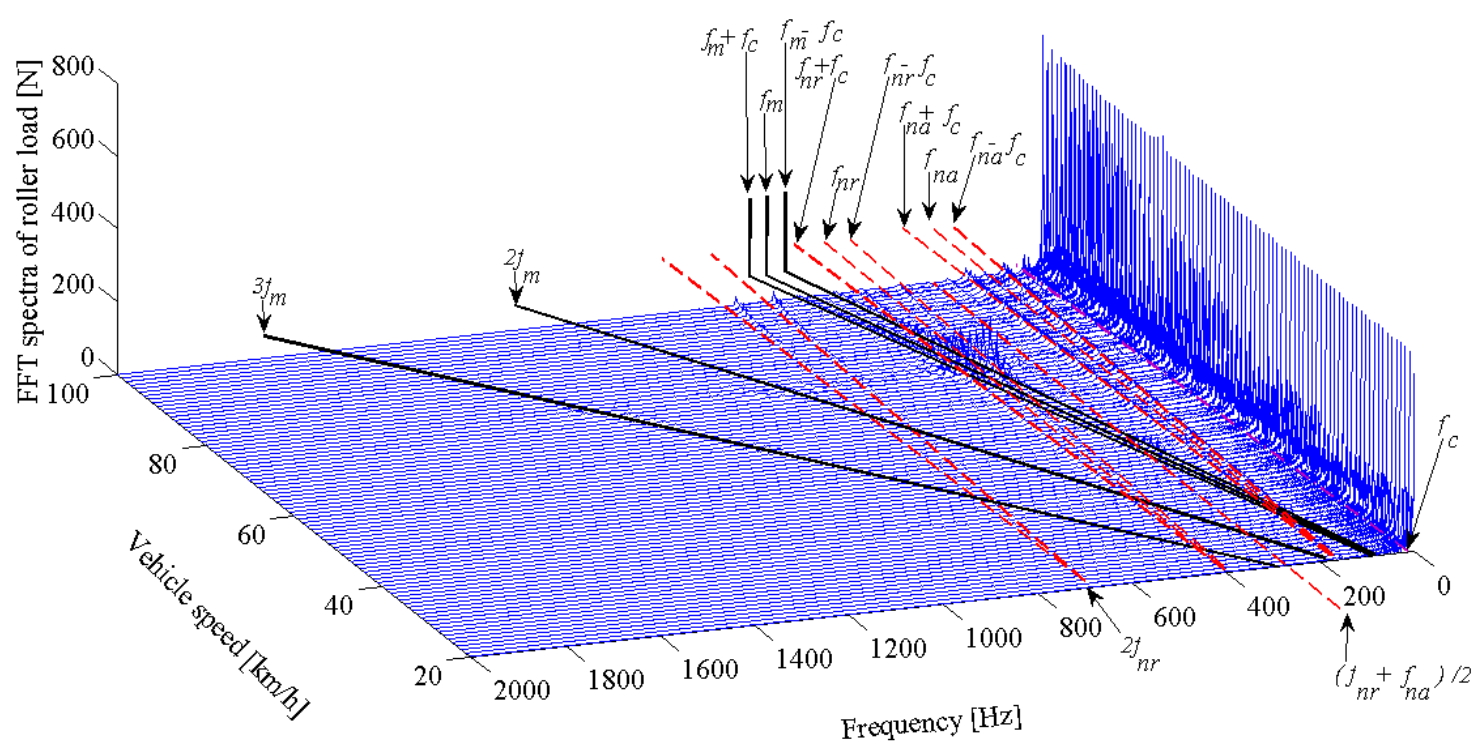

Figure 10: FFT spectra of roller load during the speed sweep $($ preload=6000N)

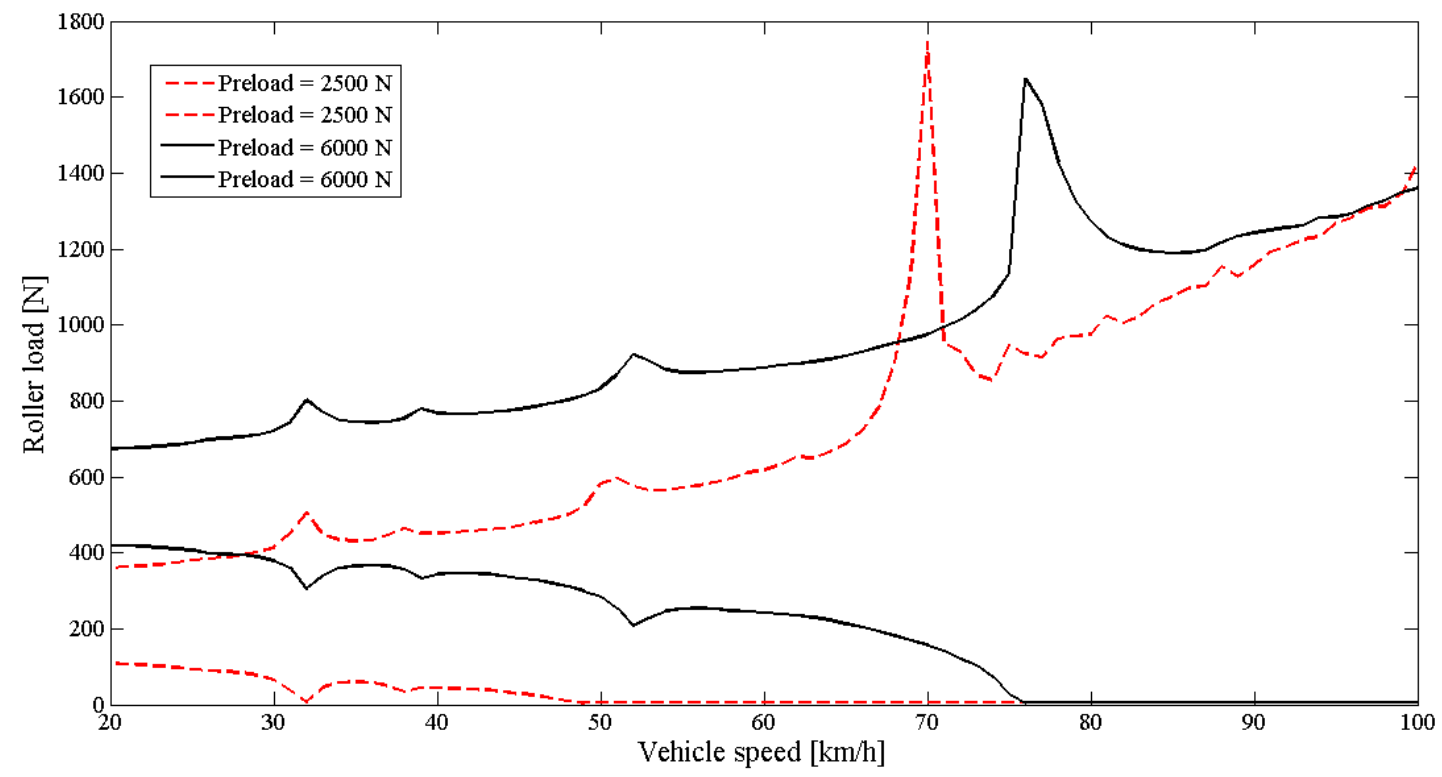

Figure 11: Maximum and minimum of roller load amplitude during the speed sweep

\subsection{Transmission efficiency:}

Aside from the DTE as a measure of vibration refinement, its efficiency is also a key attribute. Figure 12 shows the transmission efficiency of the system for different bearing 
preload values. The predicted values are in range of $99.05 \%-99.15 \%$. This range is in line with the observed values in the literature for the overall axle efficiency of $96 \%-98.5 \%$ for similar range of working conditions [46-48].

It can be observed that the higher preload worsens the transmission efficiency throughout the speed sweep. The converse is true of NVH refinement as already described above. The reason for reduced transmission efficiency with increased bearing preload is the larger variations in the DTE and radial displacements at some vehicle speeds. These occur around the natural frequency regions as seen in figures 5 and 8. Although the difference in this figure looks marginal, but the variation of inefficiency at some places is around $10 \%$ particularly near resonance. Generally, the reason of not very significant variation can be explained with the in-sensitivity of the EHL film thickness and consequently the friction to the load. It is evident from equations (11)-(19) and (22). In equation (22) the power of the load is 0.073 and therefore the variation in the boundary and viscous friction is insignificant. With larger bearing preload, the loaded region of the bearing is extended, thus less rolling elements are subject to off-loaded conditions, hence reduced bearing radial excursion. In practice, less effective damping and occurs with widely spread bearing loaded region [42]. The resulting increased radial motion an increased DTE variation causes increased friction in gear meshing contact. Hence, vibration refinement and transmission efficiency may present contradictory requirements, making a combined study of dynamics and contact mechanics an essential feature of any analysis, an approach not often undertaken in many contributions in open literature. 


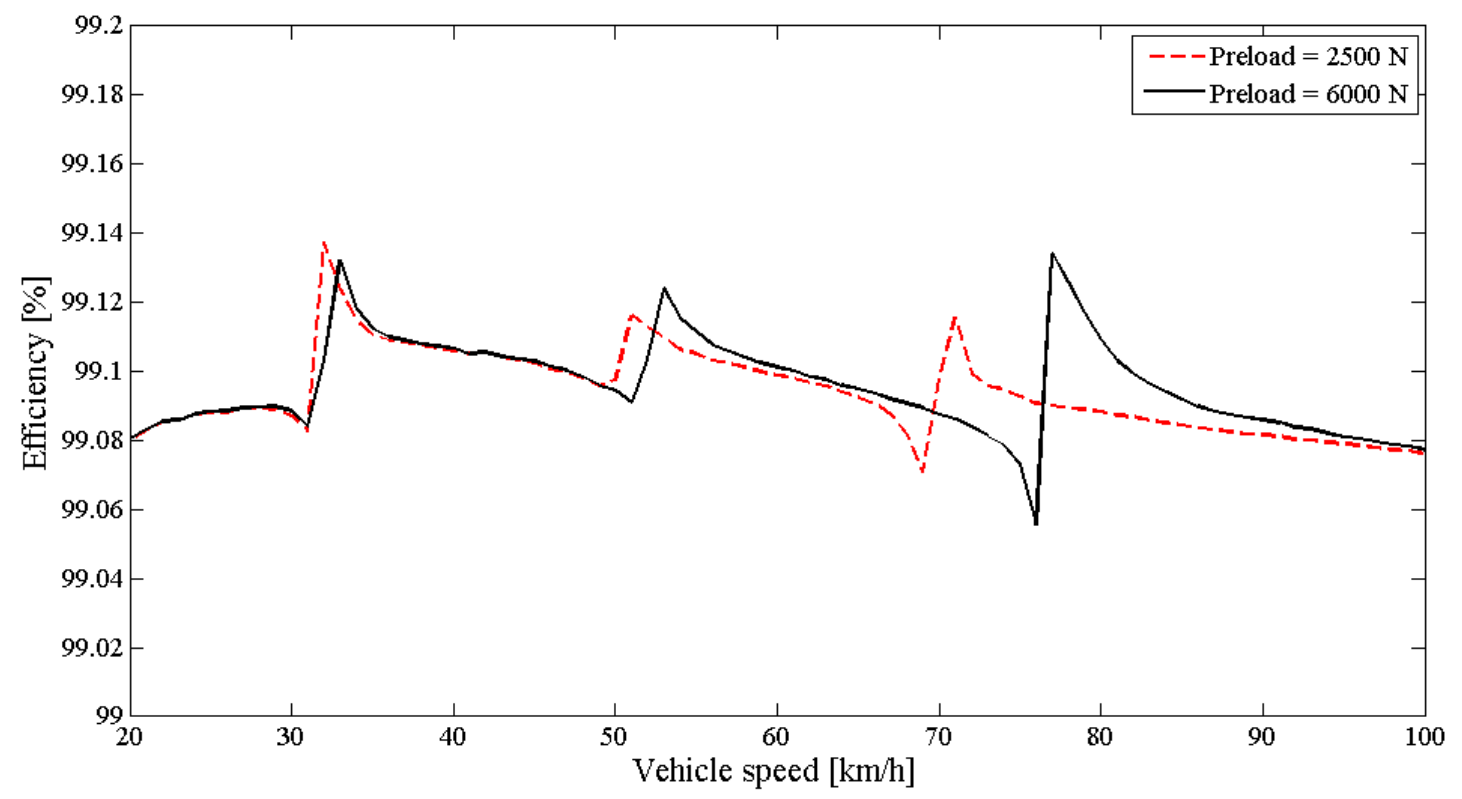

Figure 12: Transmission efficiency with different bearing preloads

\section{Conclusion}

The paper presents a tribo-dynamic model of differential hypoid gear pairs including the dynamic modelling of tapered roller bearings. The model integrates inertial dynamics of transmission and supporting bearing system with lubricated contact dynamics of hypoid gear meshing pair. This is due to physical connection between these two models requiring the multi-physics tribo-dynamic approach. Based on the presented results, following conclusions can be made:

1. It is shown that the transmitted vibration spectra from the system onto the differential casing are dominated by bearing-induced frequencies rather than that due to meshing of gears. 
2. The contribution of the latter becomes more significant with increased bearing preload which spreads the extent of bearing loaded region and thus reduces the bearing compliance effect.

3. Therefore, increased bearing preload improves vibration refinement. However, the same leads to greater fluctuation in gear pair dynamic transmission error (increased contribution at the meshing frequencies) which in turn leads to reduced transmission efficiency and increased power loss. This is something which has already been shown in the current literature with the similar qualitative behaviour.

4. The main conclusion of the investigation is that an optimal solution should be sought with an integrated tribodynamic analysis as in the current paper, since transmission efficiency and vibration refinement are key concerns and they can lead to contradictory requirements.

\section{References}

[1] M. Mohammadpour, S. Theodossiades and H. Rahnejat, Transient mixed nonNewtonian thermo-elastohydrodynamics of vehicle differential hypoid gears with starved partial counter-flow inlet boundary. Proc. IMechE, Part J: Journal of Engineering Tribology, 228(10) (2014) 1159-1173

[2] J.R. Ottewill, S.A. Neild and R.E. Wilson, An investigation into the effect of tooth profile errors on gear rattle. Journal of Sound and Vibration, 329(17) (2010) 3495-3506

[3] S. Theodossiades, O. Tangasawi and H. Rahnejat, Gear teeth impacts in hydrodynamic conjunctions promoting idle gear rattle. Journal of Sound and Vibration, 303 (3) (2007) 632-658 
[4] O. Tangasawi, S. Theodossiades and H. Rahnejat, Lightly loaded lubricated impacts: idle gear rattle. Journal of Sound and Vibration, 308(3) (2007) 418-430

[5] M. De la Cruz, S. Theodossiades and H. Rahnejat, An investigation of manual transmission drive rattle. Proc. IMechE, Part K: Journal of Multi-body Dynamics, 224(2) (2010) 167-181

[6] M.T. Menday, H. Rahnejat and M. Ebrahimi, Clonk: an onomatopoeic response in torsional impact of automotive drivelines. Proc. IMechE, Part D: Journal of Automobile Engineering, 213(4) (1999) 349-357

[7] S.J. Kim and S.K. Lee, Experimental identification of a gear whine noise in the axle system of a passenger van. International Journal of Automotive Technology, 8(1) (2007) $75-82$

[8] G. Koronias, S. Theodossiades, H. Rahnejat, and T. Saunders, Axle whine phenomenon in light trucks: a combined numerical and experimental investigation. Proc. IMechE, Part D: Journal of Automobile Engineering, 225(7) (2011) 885-894

[9] H. N. Ozguven, D.R. Houser, Dynamic analysis of high speed gears by using loaded static transmission error. Journal of Sound and Vibration 125 (1988) 71-83

[10] H. N. Ozguven, D.R. Houser, Mathematical models used in gear dynamics- A review. Journal of Sound and Vibration, 121(3) (1988) 383-411

[11] R.J. Comparin, R. Singh, Non-linear frequency response characteristics of an impact gear. Journal of Sound and Vibration, 134 (1989) 259-290 
[12] A. Kahraman and R. Singh, Interactions between the time varying mesh stiffness and clearance nonlinearities in a geared system. Journal of Sound and Vibration, 146(1) (1991) 135-156

[13] A. Kahraman and R. Singh, Non-linear dynamics of a geared-rotor bearing system with multiple clearances. Journal of Sound and Vibration, 144 (1991) 469-506

[14] M. Amabili and A. Rivola, Dynamic analysis of spur gear pairs: steady-state response and stability of the SDOF model with time varying mesh damping. Mechanical Systems and Signal Processing, 11 (1997) 375-390

[15] E.P. Remmers, Dynamics of automotive rear axle gear noise. SAE Technical Paper, 1971710114

[16] S. Kiyono, Y. Fujii and Y. Suzuki, Analysis of vibration of bevel gears. Bulletin of JSME, 24 (1981) 441-446

[17] M.G. Donley, T.C. Lim and G.C. Steyer, Dynamic analysis of automotive gearing systems. Journal of Passenger Cars, 101 (1992) 77-87

[18] Y. Cheng and T.C. Lim, Dynamic analysis of high speed hypoid gears with emphasis on automotive axle noise problem. Proc. ASME Power Transmission and Gearing Conf., DETC98/PTG-5784, Atlanta, GA, 1998

[19] Y. Cheng and T.C. Lim, Dynamics of hypoid gear transmission with time-varying mesh. Proc. ASME Power Transmission and Gearing Conf., DETC2000/PTG-14432, Baltimore, MD, 2000 
[20] X. Jiang, Non-linear Torsional Dynamic Analysis of Hypoid Gear Pairs. MSc Thesis, The University of Alabama, 2002

[21] J. Wang, T.C. Lim and M. Li, Dynamics of a hypoid gear pair considering the effects of time-varying mesh parameters and backlash nonlinearity. Journal of Sound and Vibration, 229 (2) (2007) 287-310

[22] I. Karagiannis, S. Theodossiades and H. Rahnejat, On the dynamics of lubricated hypoid gears. Mechanism and Machine Theory, 48 (2012) 94-120.

[23] A.N. Grubin, Contact stresses in toothed gears and worm gears. Book 30 CSRI for Technology and Mechanical Engineering , Moscow, DSRI Trans., 337, 1949

[24] M. Mohammadpour, S. Theodossiades, H. Rahnejat, and P. Kelly. Transmission efficiency and noise, vibration and harshness refinement of differential hypoid gear pairs. Proc. IMechE, Part K: Journal of Multi-body Dynamics, 228(1) (2014) 19-33

[25] R.J. Chittenden et al. A theoretical analysis of the isothermal elastohydrodynamic lubrication of concentrated contacts. II. General Case, with lubricant entrainment along either principal axis of the Hertzian contact ellipse or at some intermediate angle. Proc. Royal Soc.,. series A: Mathematical and Physical Sciences 397(1813) (1985) 271-294.

[26] M. Mohammadpour, S. Theodossiades, H. Rahnejat, Multi-physics investigations in differential hypoid gears. Journal of Vibration and Acoustic, 136(4) (2014) 041007

[27] C.R. Evans and K. L. Johnson. Regimes of traction in elastohydrodynamic lubrication. Proc. IMechE, Part C: Journal of Mechanical Engineering Science 200(5) (1986) 313-324. 
[28] M. Mohammadpour, I. Mirzaee, S. Khalilarya, A Mathematical-Numerical Model to Calculate Load Distribution, Contact Stiffness and Transmission Error in Involute Spur Gears. ASME IDETC/PTG2009 Conference, 2009, USA.

[29] F. L. Litvin and A. Fuentes, Gear geometry and applied theory. Cambridge University Press, 2004

[30] M. Kolivand and A. Kahraman. A load distribution model for hypoid gears using ease-off topography and shell theory. Mechanism and Machine Theory 44(10) (2009) 1848-1865

[31] S. Vijayakar, CALYX Manual. Advanced Numerical Solutions Inc., Columbus, Ohio, 2000

[32] M. Fujii, Y. Nagasaki and M. Nohara, Differences in dynamic behavior between straight and skew bevel gears. Trans. JSME, 63(613) (1997) 3229-3234

[33] Y. Li, G. Li and Z. Ling, Influence of asymmetric mesh stiffness on dynamics of spiral bevel gear transmission system. Mathematical Problems in Engineering 2010

[34] J. Yang and T. Lim, Dynamics of Coupled Nonlinear Hypoid Gear Mesh and Timevarying Bearing Stiffness Systems. SAE paper 2011-01-1548, 2011

[35] P. Dietl, J. Wensing and G. C. Van Nijen, Rolling bearing damping for dynamic analysis of multi-body systems-experimental and theoretical results. 214 (33) (2000) 3343 
[36] T.D. Gillespie, Fundamentals of Vehicle Dynamics. Society of Automotive Engineering, Inc. Pa, USA, 1992

[37] J. A. Greenwood and J. H. Tripp, The contact of two nominally flat rough surfaces. Proc. IMechE, Journal of Mech. Eng. Sci., 185 (1971) 625-633

[38] S. Bair and W.O. Winer, Shear strength measurements of lubricants at high pressure. Trans ASME, Journal of Tribology, 101(3) (1979) 251-257.

[39] R. Gohar and H. Rahnejat, Fundamental of Tribology. Imperial college press, London, 2008

[40] H. Xu and A. Kahraman, Prediction of friction-related power losses of hypoid gear pairs. Proc. IMechE, Journal of Multi-body Dynamics., 221 (2007) 387-400

[41] M. Mohammadpour, S. Theodossiades and H. Rahnejat, Elastohydrodynamic lubrication of hypoid gears at high loads. Proc. IMechE., Part J: Journal of Engineering. Tribology, 226 (3) (2012) 183-198

[42] H. Rahnejat and R. Gohar, The vibrations of radial ball bearings. Proc. IMechE, Part C: Journal of Mech. Eng. Sci., 199 (1985) 181-93

[43] T. Harris and M.N. Kotzalas, Advanced Concepts of Bearing Technology. Taylors and Francis, 2007

[44] H. Rahnejat, Computational modelling of problems in contact dynamics. Engineering Analysis, 2(4) (1985) 192-197 
[45] A. Mostofi and R. Gohar, Elastohydrodynamic lubrication of finite line contacts. Trans ASME, Journal of Tribology, 105(4) (1983) 598-604.

[46] Kolekar, A. S., Olver, A. V., Sworski, A. E., \& Lockwood, F. E.. The efficiency of a hypoid axle-a thermally coupled lubrication model. Tribology International, 59 (2013) 203-209.

[47] Xu, H., Houser, D. R., \& Kahraman, A.. A Model to Predict Friction Losses by Hypoid Gears. (2005) AGMA.

[48] Hurley, J. D. (2009). An Experimental Investigation of Thermal Behavior of an Automotive Rear Axle (Doctoral dissertation, The Ohio State University).

\section{Appendix 1:}

Table A1. Gear pair parameters

\begin{tabular}{|c|c|c|}
\hline Parameter & Pinion & Gear \\
\hline Teeth number & 13 & 36 \\
\hline Facewidth (mm) & 33.851 & 29.999 \\
\hline Face angle & 29.056 & 59.653 \\
\hline Pitch angle & 29.056 & 59.653 \\
\hline Root angle & 29.056 & 59.653 \\
\hline Spiral angle & 45.989 & 27.601 \\
\hline Pitch apex (mm) & -9.085 & 8.987 \\
\hline Face apex (mm) & 1.368 & 10.948 \\
\hline Outer cone distance & 83.084 & 95.598 \\
\hline Offset (mm) & 24.0000028 & 24 \\
\hline Sense (Hand) & Right & Left \\
\hline
\end{tabular}


Table A2: Bearing particulars and working conditions

\begin{tabular}{|c|c|}
\hline Inner race bore & $40[\mathrm{~mm}]$ \\
\hline Inner race diameter & $50[\mathrm{~mm}]$ \\
\hline Outer race diameter & $75.4[\mathrm{~mm}]$ \\
\hline Roller diameter & $12.7[\mathrm{~mm}]$ \\
\hline Outer race outside diameter & $83.7[\mathrm{~mm}]$ \\
\hline Roller length & $22[\mathrm{~mm}]$ \\
\hline Dub-off radius & $50[\mathrm{~mm}]$ \\
\hline Dub-off length & $3[\mathrm{~mm}]$ \\
\hline Number of rollers & 12 \\
\hline Inner race-roller-outer race stiffness & $5 \mathrm{e} 8[\mathrm{~N} / \mathrm{m}]$ \\
\hline Shaft rotational speed & $209[\mathrm{rad} / \mathrm{s}]$ \\
\hline Cage set speed & $83.26[\mathrm{rad} / \mathrm{s}]$ \\
\hline External load & $1500[\mathrm{~N}]$ \\
\hline System mass & 50 [kg] \\
\hline Radial interface & 10 [um] \\
\hline
\end{tabular}

Table A3. Input operating conditions

\begin{tabular}{|c|c|}
\hline Frontal area & $2.2 \mathrm{~m} 2$ \\
\hline Coefficient of rolling & 0.0166 \\
\hline Drag coefficient & 0.33 \\
\hline Air density & $1.22 \mathrm{~kg} / \mathrm{m} 3$ \\
\hline Vehicle weight & $1300 \mathrm{~kg}$ \\
\hline Tyre (type) & $195 / 65 \mathrm{R} 16$ \\
\hline
\end{tabular}


Table A4. Physical properties of the lubricant and solids

\begin{tabular}{|c|c|}
\hline Pressure viscosity coefficient & $2.38310-8[\mathrm{~Pa}-1]$ \\
\hline Atmospheric dynamic viscosity & $0.0171[\mathrm{~Pa} . \mathrm{s}]$ \\
\hline Lubricant Eyring shear stress & $2[\mathrm{MPa}]$ \\
\hline Heat capacity of fluid & $0.14\left[\mathrm{~J} / \mathrm{kg}^{\circ} \mathrm{K}\right]$ \\
\hline Thermal conductivity of fluid & $2000\left[\mathrm{~W} / \mathrm{m}^{\circ} \mathrm{K}\right]$ \\
\hline Modulus of elasticity of contacting solids & $210[\mathrm{GPa}]$ \\
\hline Poisson's ratio of contacting solids & 0.3 \\
\hline Density of contacting solids & $7850[\mathrm{~kg} / \mathrm{m} 3]$ \\
\hline Thermal conductivity of contacting solids & $46\left[\mathrm{~W} / \mathrm{m}^{\circ} \mathrm{K}\right]$ \\
\hline Heat capacity of contacting solids & $470\left[\mathrm{~J} / \mathrm{kg}^{\circ} \mathrm{K}\right]$ \\
\hline Surface roughness of solids, Ra & $0.5 \mu \mathrm{m}$ \\
\hline
\end{tabular}

